\title{
Pengukuran Tingkat Kematangan Pada E-Dishub Pada Domain Deliver And Support Menggunakan COBIT 4.1 (Studi Kasus : Dinas Perhubungan Kota Surabaya)
}

\author{
Ronggo Alit ${ }^{1 *}$,Yisti Vita Via ${ }^{2}$,Chrystia Aji Putra ${ }^{3}$ \\ ${ }^{1,2,3}$ Program Studi Informatika, Fakultas Ilmu Komputer, Universitas Pembangunan Nasional "Veteran” Jawa Timur \\ *Corresponding author email: ronggo.if@upnjatim.ac.id
}

\begin{abstract}
Abstrak- Dinas Perhubungan Kota Surabaya merupakan salah satu instansi pemerintah yang berada di Kota Surabaya yang bergerak dalam bidang pelayanan transportasi dan lalu lintas. Dinas Perhubungan Kota Surabaya memiliki misi dalam meningkatkan teknologi informasi di bidang perhubungan. Dalam pemanfatan teknologi tersebut masih kurang optimal, ditandai dengan belum adanya standar operasional yang baku di e-dishub, pengelolaan sumber daya manusia yang masih belum optimal serta masalah keamanan yang merugikan instansi akibat dari kehilangan data-data. Dalam penelitian ini fokus pada domain DS (Deliver and Support). Sub domain yang dipilih yaitu DS5 mengenai memastikan keamanan sistem dan DS11 mengenai mengelola data. Hasil yang didapat yaitu indeks maturity (rata-rata) tingkat kematangan kondisi saat ini EDishub yaitu 1,8 yang masuk ke dalam level 2 (repetable but intuitive atau berulang). Yang berarti pada kondisi ini dinas sudah mengalami perkembangan, sudah ada prosedur untuk menjalankan proses yang didefinisikan, namun belum ada pelatihan formal dan prosedur komunikasi yang standar.
\end{abstract}

Kata Kunci- E-Dishub, Deliver and Support, COBIT 4.1.

\section{Pendahuluan}

Penerapan teknologi informasi harus disesuaikan dengan kebutuhan institusi agar dapat mencapai tujuan institusi tersebut. Mencapai tujuan institusi tersebut diperlukan suatu perencanaan dan implementasi teknologi informasi yang selaras dengan perencanaan dan strategi bisnis organisasi yang telah didefinisikan. Penerapan TI yang selaras dengan tujuan institusi tersebut akan tercapai apabila didukung oleh sistem tata kelola yang baik (IT Governance) yang dimulai dari tahap perencanaan, implementasi dan evaluasi. Tata kelola teknologi informasi didefinisikan sebagai struktur hubungan dan proses untuk mengarahkan dan mengontrol suatu institusi dalam mencapai tujuannya dengan menambahkan nilai dan menyeimbangkan resiko terhadap teknologi informasi dan proses-prosesnya, agar layanan TI berjalan sesuai dengan yang diharapkan, perlu ditunjang dengan tata kelola TI[1].

Kota Surabaya merupakan salah satu kota di propinsi Jawa Timur yang menggunakan teknologi dalam setiap aktivitas pemerintahannya[2]. Dinas Perhubungan Kota Surabaya merupakan salah satu instansi pemerintah di kota Surabaya yang menerapkan teknologi informasi dalam pelayanan kepada masyarakat atau pelayanan publik. Salah satu penerapan teknologi informasi pada Dinas Perhubungan Kota Surabaya yaitu dengan adanya E-Dishub. E-Dishub merupakan aplikasi yang memberikan informasi seputar transportasi mulai jurusan angkutan kota hingga pengajuan perizinan, yang tersaji dengan jelas dan informasi seputar lalu lintas wilayah Surabaya dapat dilihat dan dipantau secara langsung dan up todate. Dalam perkembangannnya Dinas Perhubungan melakukan perluasan organisasi dengan mengikuti perkembangan Kota Surabaya yang semakin pesat. Dengan berkembangnya Kota Surabaya, Dinas Perhubungan melakukan perluasan seperti pengembangan pengelolaan angkutan masal dan pengelolaan sistem informasi transportasi berbasis teknologi informasi [3].

Berdasarkan hasil wawancara yang telah dilakukan mengenai pelaksanaan tata kelola TI ditemukan beberapa masalah yaitu yang pertama terjadi masalah keamanan dalam E-Dishub diakibatkan dari hacking oleh orang yang tidak bertanggung jawab. Dampak dari masalah yang ditimbulkan tersebut yaitu kehilangan data-data yang terdapat dalam EDishub. Kedua yaitu dalam pengelolaan pelu dlakuakn lebih optimal agar saat terjadai masalah seperti hacking yang menyerang, data-data yang diserang telah terdapat cadangannya atau dilakukan backup data. Domain yang dipilih yaitu DS5 mengenai memastikan kemanan sistem dan DS11 mengenai mengelola data.

Penelitian bertujuan untuk mengetahui tingkat kematangan tata kelola TI yang telah diterapkan oleh Dinas Perhubungan Kota Surabaya. Dari penelitian yang dilakukan akan menghasilkan maturity level untuk mengetahui tingkat kematangan saat ini pada dinas. Hasil dari penelitina ini yaitu rekomendasi yang nantinya diharapkan sebagai bahan pertibangan untuk meningkatkan tata kelola TI. Tata kelola teknologi informasi merupakan suatu bagian dari pengelolaan suatu perusahaan secara keseluruhan yang terdiri atas kepemimpinan dan struktur organisasi dari proses yang ada untuk memastikan kelanjutan TI organisasi dan pengembangan strategi serta tujuan organisasi. Cobit (Control Objectives for Information and Related Technology ) merupakan sekumpulan dokumentasi dan panduan yang mengarahkan pada TI Governance yang dapat membantu auditor, manajemen dan pengguna (user) untuk menjembatani pemisah antara model kendali bisnis dan model kendali teknologi informasi. COBIT pertama kali dikembangkan pada tahun 1996 oleh IT Governance Institute (ITGI) yang merupakan bagian dari Information Systems Audit and Control Association (ISACA)[4]. 


\section{TINJAUAN PUSTAKA}

\section{A. COBIT 4.1}

COBIT adalah sekumpulan dokumentasi best practices untuk IT Governance yang dapat membantu auditor, pengguna (user), dan manajemen, untuk menjembatani gap antara risiko bisnis, kebutuhan control dan masalah-masalah teknis TI. Aktivitas teknologi informasi pada COBIT 4.1 didefinisikan ke dalam empat domain yaitu Perencanaan dan Pengorganisasian/Plan and Organise (PO), Penyampaian Layanan dan Dukungan/Deliver and Support (DS), serta Pengadaan dan Implementasi/Acquire and Implement (AI), Monitor dan Evaluasi/Monitor and Evaluate (ME). Keempat domain tersebut saling berhubungan. PO menghasilkan arahan terhadap penyampaian solusi (AI) dan penyampaian layanan (DS). AI menghasilkan solusi dan membuatnya menjadi layanan. DS menerima solusi dan membuatnya dapat digunakan oleh user. ME memonitor semua proses untuk memastikan bahwa arahan yang ada telah dilaksanakan/diikuti.
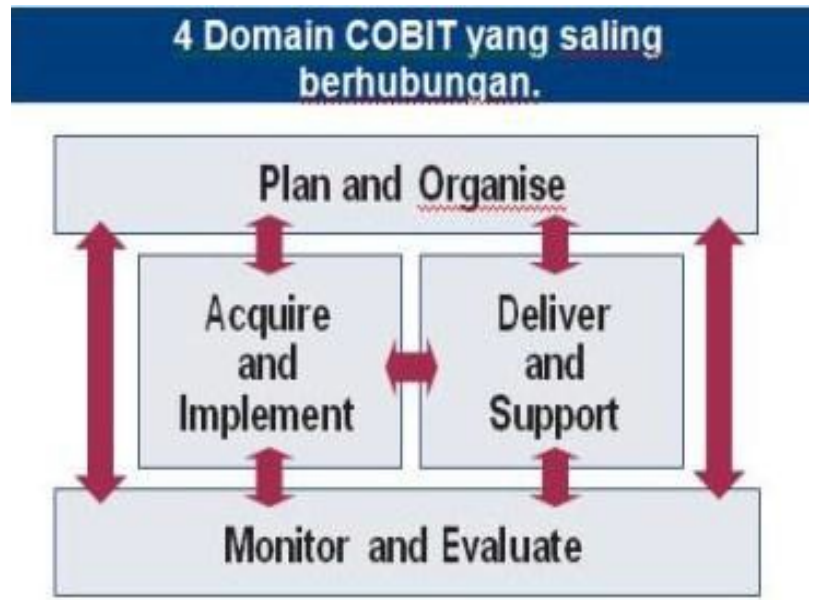

Gbr. 1. Empat Domain dalam COBIT [5]

Dalam empat domain tersebut, terdapat 34 proses TI yang diidentifikasi oleh COBIT, yang dipakai secara umum. Proses-proses ini dapat digunakan untuk memastikan kelengkapan aktifitas dan tanggung jawab, namun tidak semua proses harus diaplikasikan, dapat pula di kombinasikan, tergantung pada keperluan perusahaan.COBIT juga mendefinisikan sasaran kendali untuk setiap 34 proses tersebut. Sasaran kendali TI (IT control objective) merupakan sekumpulan pernyataan atau syarat yang menjadi pertimbangan oleh manajemen untuk mendapatkan kontrol yang efektif terhadap setiap proses TI.

Komponen COBIT yang berisi sebuah respon kerangka kerja untuk kebutuhan manajemen bagi pengukuran dan pengendalian TI dengan menyediakan alat-alat untuk menilai dan mengukur kemampuan TI organisasi. COBIT digunakan untuk melakukan audit tingkat kematangan tata kelola prses- proses penyelenggaraan dalam pengelolaan teknolog informasi. COBIT telah dikembangkan sebagai sebuah aplikasi umum dan telah diterima menjadi standar yang baik bagi praktek pengendalian dan keamanan TI yang menyediakan sebuah kerangka kerja bagi pengelola, user, audit sistem informasi, dan pelaksana pengendalian dan keamanan. Pedoman COBIT memungkinkan perusahaan atau institusi untuk mengimplementasikan pengaturan TI secara efektif dan pada dasarnya dapat diterapkan di seluruh organisasi. Khususnya, komponen pedoman manajemen COBIT yang berisi sebuah respon kerangka kerja untuk kebutuhan manajemen bagi pengukuran dan pengendalian TI dengan menyediakan alat-alat untuk menilai dan mengukur kemampuan TI perusahaan atau institusi untuk 34 proses TI COBIT.

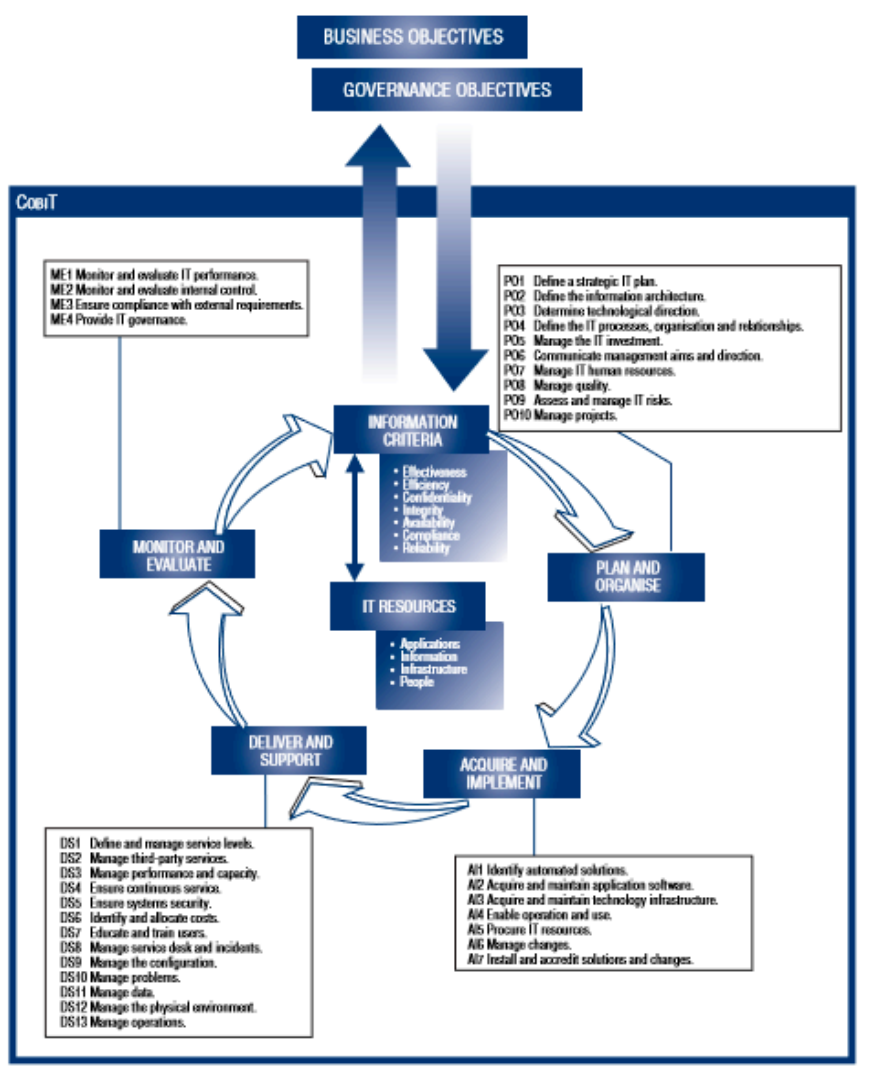

Gbr. 2. Kerangka Kerja Cobit [5]

Keempat domain tersebut memiliki 34 proses TI dengan penjelasan sebagai berikut :

1. Plan and Organise, mencakup strategi, taktik dan identifikasi tentang bagaimana TI mampu berkontribusi terhadap suatu pencapaian dari tujuan bisnis.

2. Acquire and Implement mewujudkan strategi dengan pemenuhan sumber daya teknologi informasi. 
3. Deliver and Support berkaitan dengan layanan yang diperlukan mencakup pengelolaan keamanan, dukungan layanan, untuk pengguna, manajemen data dan fasilitas operasional.

4. Monitor and Evaluate mengenai penilaian seluruh proses teknologi informasi secara rutin guna menjaga kualitas dan ketaatan sesuai kriteria pengendalian.

\section{B. Maturity Level}

IT Maturity Model merupakan model yang digunakan untuk mengukur tingkat kematangan pengelolaan teknologi informasi dalam suatu organisasi. Maturity Model terdiri dari lima tingkat kematangan pengelolaan IT, meliputi : tingkat 0 (non-existent), tingkat 1 (initial), tingkat 2 (repeateable), tingkat 3 (defined), tingkat 4 (managed) dan tingkat 5 (optimised). Pendefinisian model kematangan suatu proses teknologi informasi mengacu pada kerangka kerja COBIT secara umum adalah sebagai berikut[6] :

1. Level 0 (Non-existent) : Tingkatan paling kecil, dimana tidak terdapat proses yang terkait

2. Level 1 (initial/Ad Hoc) : Kegiatan proses telah dilaksanakan. Namun belum ada standar prosedur, sehingga masih bersifat reaktif

3. Level 2 (Repeatable but intuitive) : Menemukan pengembangan/pola yang teratur dan terarah untuk mengelola proses, namun tidak dikomunikasikan dan tergantung pada pengetahuan individu

4. Level 3 (defined) : Seluruh proses/prosedur telah didokumentasikan dan dilaksanakan melalui pelatihan.namun belum terintegrasi dan tidak mungkin penyimpangan proses akan terdeteksi

5. Level 4 (managed) : Tahap dimana prosedur telah diterapkan dan terintegrasi, dapat dipantau dan diukur, namun otomasi terbatas pada proses tertentu

6. Level 5 (optimized ) : Praktik terbaik telah diikuti, dikembangkan dan diotomasi pada system, berdasarkan hasil dari perbaikan terus menerus

\section{Metodologi}

Metode penelitian dibuat berdasarkan teori COBIT 4.1 yang menjelaskan semua tahapan yang akan digunakan pada penelitian ini. Penelitian ini menggunakan metode kualitatif dalam melihat suatu kejadian, mengumpulkan data, menganalisa informasi dan melaporkan hasilnya secara sistematis. Kerangka penelitian menggambarkan konsep dan pemikrian utama dalam melakukan penelitian ini.

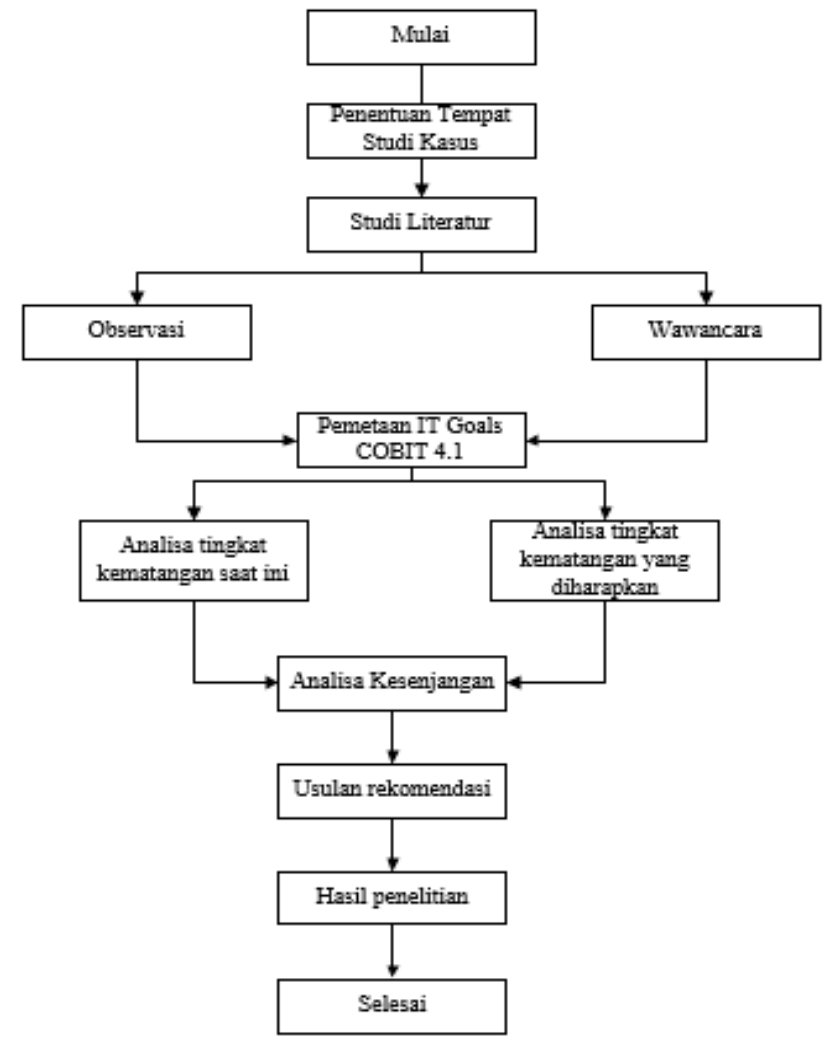

Gbr. 3. Alur Penelitian

Sebelum melakukan sebuah penelitian, seorang peneliti harus menentukan tempat sebagai objek atau studi kasus penelitian. Tempat penelitian digunakan sebagai tempat untuk analisa data-data yang diperlukan penulis dalam menyelesaikan penelitian. Studi literatur adalah serangkaian kegiatan yang menyangkut dengan metode pengumpulan data pustaka, membaca dan mencatat, serta mengelola bahan penelitian dengan menelusuri sumber-sumber tulisan yang pernah dibuat sebelumnya. Sumber dapat berupa buku, jurnal dan artikel, dengan tujuan untuk menambah wawasan yang luas terkait objek yang akan diteliti dan sebagai bahan referensi peneliti. Dan dalam studi literatur ini peneliti menentukan framework yang digunakan dalam penelitian tugas akhir. Tahap ini dilakukan pengumpulan data dalam tiga cara antara lain :

1. Wawancara

Dilakukan analisa dengan melakukan wawancara sesuai dengan batasan masalah yang telah ditentukan. Penulis mengajukan pertanyaan kepada narasumber yang bersangkutan. Penulis melakukan wawancara terhadap salah satu staf dan kepala bagian yang membawahi atau yang bertanggungjawab dalam EDishub.

2. Observasi

Pada tahap ini dilakukan untuk mengamati dan melihat secara langsung proses yang terdapat pada 
institusi untuk mendapatkan informasi-informasi yang dibutuhkan untuk melanjutkan suatu penelitian.

Pada tahapan pemetaan dilakukan identifikasi proses bisnis berdasarkan tujuan TI melalui data yang telah didapatkan dari wawancara kepada responden, observasi, studi literatur dari Dinas Perhubungan Kota Surabaya. Dari hasil wawancara dilakukan pemetaan. Setelah dilakukan pemetaan maka akan ditentukan domain dan proses TI yang digunakan penulis. Dari domain yang dihasilkan akan menghasilkan rekomendasi perbaikan terhadap permasalahan yang terjadi. Domain yang didapatkan oleh penulis setelah melakukan pemetaan yang merujuk pada IT Goals dan IT Process. Analisa tingkat kematangan saat ini (as - is) diperoleh dari data hasil wawancara dan observasi terhadap instansi. Tahap ini dilakukan dengan mengukur tingkat kematangan dari proses TI yang terpilih berdasarkan framework COBIT 4.1. Penulis akan mengajukan pertanyaan kepada narasumber mengenai level atau tingkat kematangan pada instansi untuk mendapatkan nilai tingkat kematangan saat ini. Pada tahap ini dilakukan perhitungan tingkat kematangan yang diharapkan (to-be). Perhitungan dilakukan dengan hasil dari analisa kondisi saat ini. Penilaian tingkat kematangan yang diharapkan akan menghasilkan nilai kematangan yang diharapkan (to-be) dan digunakan sebagai acuan untuk pengembangan tata kelola yang lebih baik kedepannya pada instansi. Pada tahap ini dilakukan analisa kesenjangan yang bertujuan untuk memberikan kemudahan dalam memberikan rekomendasi atau perbaikan. Pemberian nilai untuk analisa kesenjangan diperoleh dari perhitungan analisa tingkat kematangan yang diharapkan (to-be) dan analisa tingkat kematangan saat ini (as-is). Nilai kesenjangan diperoleh dari nilai tingkat kematangan yang diharapkan (tobe) dikurangi nilai kematangan saat ini (as-is). Usulan rekomendasi atau perbaikan merupakan bentuk saran dari hasil penelitian yang telah dilakukan oleh peneliti. Rekomendasi diperoleh dari penilaian yang dilakukan terhadap tingkat kematangan saat ini dan tingkat kematangan yang diharapkan. Rekomendasi dibuat untuk saran yang dapat dijalankan atau dikembangkan instansi secara bertahap atau dapat diterapkan beberapa tahun mendatang. Hasil penelitian merupakan tahap akhir dalam penelitian yang dilakukan. Data-data hasil analisa yang telah dilakukan akan dijadikan satu dan dibuat laporan untuk kemudian dijadikan buku dan menjadi bukti bahwa penelitian telah dilakukan oleh peneliti.

\section{HASIL DAN PEMBAHASAN}

Mengeni hasil penelitian dari data yang sudah diperoleh dari Dinas Perhubungan Kota Surabaya. Data-data tersebut dapat dari hasil wawancara dan observasi yang diolah sesuai framework COBIT 4.1. Pada tahap identifikasi control objective dilakukan identifikasi control objective yang akan digunakan selama penelitian. Tabel control objective diperoleh dari pemilihan detail control yang terdapat dalam proses TI.

TABEL I

Detail Control Objective

\begin{tabular}{|c|c|c|}
\hline Permasalahan & Tujuan TI & $\begin{array}{c}\text { Control } \\
\text { Objectives }\end{array}$ \\
\hline $\begin{array}{c}\text { Keamanan Sistem } \\
\text { karena pada tahun } \\
\text { 2018 sistem pernah } \\
\text { terkena hacking }\end{array}$ & $\begin{array}{c}\text { Kemampuan } \\
\text { memberikan } \\
\text { penjelasan dan } \\
\text { perlindungan } \\
\text { terhadap aset- } \\
\text { aset TI (14) }\end{array}$ & $\begin{array}{c}\text { DS5 (Memastikan } \\
\text { keamanan sistem) }\end{array}$ \\
& & \\
& & \\
\hline
\end{tabular}

Dengan adanya domain proses DS5 dapat mengetahui bagaimana pihak perusahaan menjaga integrasi informasi dan infrastruktur pengelohan dan meminimalkan dampak dari kerentanan keamanan dan insiden. Dengan adanya domain proses DS11 dapat mengetahui bagaimana proses mengoptimalkan informasi dan memastikan bahwa informasi yang tersedia sesuai dengan kebutuhan.

\section{A.Maturity Level Saat Ini (as-is)}

Didalam proses TI DS5 (Memastikan keamanan sistem) terdapat beberapa detail control objective yang digunakan. Penjelasan lebih detail tentang penilaian tingkat kematangan DS5 saat ini ( as -is) ada pada Tabel 2

TABEL 2

TABEL NILAI TINGKAT KEMATANGAN SAAT INI PADA SUB DOMAIN DS5

\begin{tabular}{|c|l|c|}
\hline \multicolumn{1}{|c|}{ Sub Domain } & \multicolumn{1}{|c|}{$\begin{array}{c}\text { Detail Control } \\
\text { Objective }\end{array}$} & Nilai \\
\hline \multirow{5}{*}{$\begin{array}{l}\text { DS5 Memastikan } \\
\text { Keamanan Sistem }\end{array}$} & $\begin{array}{l}\text { DS5.1 Manajemen } \\
\text { Keamanan TI }\end{array}$ & $\begin{array}{l}\text { DS5.6 Definisi Insiden } \\
\text { Keamanan }\end{array}$ \\
\cline { 2 - 3 } & \begin{tabular}{l} 
Identitas \\
\cline { 2 - 3 }
\end{tabular} & $\begin{array}{l}\text { DS5.7 Perlindungan } \\
\text { Teknologi Keamanan }\end{array}$ \\
\cline { 2 - 3 } & Rata-rata & 2 \\
\hline
\end{tabular}

Dari tabel dan diagram diatas dijelaskan mengenai penilaian tingkat kematangan saat ini pada sub domain DS5 ( Memastikan Keamanan Sistem). Pada DS5 didapatkan nilai 1,75 pada level 2 (berulang). 
TABEL 3

TABEL NILAI TINGKAT KEMATANGAN SAAT INI PADA SUB DOMAIN DS1 1

\begin{tabular}{|l|l|c|}
\hline \multicolumn{1}{|c|}{ Sub Domain } & \multicolumn{1}{|c|}{ Detail Control Objective } & Nilai \\
\hline \multirow{5}{*}{$\begin{array}{l}\text { DS11 Kelola } \\
\text { Data }\end{array}$} & $\begin{array}{l}\text { DS11.1 Persyaratam Bisnis } \\
\text { untuk Manajemen Data }\end{array}$ & 2 \\
\cline { 2 - 3 } & DS11.4 Pembuangan & 2 \\
\cline { 2 - 3 } & $\begin{array}{l}\text { DS11.5 Pencadangan dan } \\
\text { Pemulihan }\end{array}$ & 2 \\
\cline { 2 - 3 } & Rata-rata & 2 \\
\hline
\end{tabular}

Dari tabel dan diagram diatas dijelaskan mengenai penilaian tingkat kematangan saat ini pada sub domain DS11 (Kelola Data). Pada DS11 didapatkan nilai 2 pada level 2 (berulang).

B. Maturity Level yang diharapkan (to - be)

TABEL 4

TABEL LEVEL YANG DIHARAPKAN

\begin{tabular}{|c|c|l|c|c|}
\hline Domain & $\begin{array}{c}\text { Sub } \\
\text { Domain }\end{array}$ & Detail Kontrol & $\begin{array}{c}\text { Nilai } \\
\text { Saat } \\
\text { Ini }\end{array}$ & $\begin{array}{c}\text { Nilai yang } \\
\text { Diharapkan }\end{array}$ \\
\hline DS & DS5 & $\begin{array}{l}\text { DS5.1 } \\
\text { Manajemen } \\
\text { Keamanan TI }\end{array}$ & 1 & 4 \\
\hline & $\begin{array}{l}\text { DS5.3 } \\
\text { Manajemen } \\
\text { Identitas }\end{array}$ & 2 & 4 \\
\hline & $\begin{array}{l}\text { DS5.6 Definisi } \\
\text { Insiden Keamanan }\end{array}$ & 2 & 4 \\
\hline DS11 & $\begin{array}{l}\text { DS5.7 } \\
\text { Perlindungan } \\
\text { Teknologi } \\
\text { Keamanan }\end{array}$ & $\begin{array}{l}\text { Persyaratam } \\
\text { Bisnis untuk } \\
\text { Manajemen Data }\end{array}$ & $\begin{array}{l}\text { DS11.4 } \\
\text { Pembuangan }\end{array}$ & 4 \\
\hline & $\begin{array}{l}\text { DS11.5 } \\
\text { Pencadangan dan } \\
\text { Pemulihan }\end{array}$ & 2 & 4 \\
\hline & & 2 & 4 \\
\hline & & & 4 \\
\hline
\end{tabular}

Dari Tabel diatas, menjelaskan mengenai penilaian tingkat kematangan yang diharapkan pada proses TI - DS5 (Memastikan Keamanan Sistem) dan DS11 (Kelola Data) Sesuai dengan rata - rata dari masing masing responden, yaitu 4 yang berarti termasuk pada level 4 (Diatur dan Terukur).

\section{Tingkat Kesenjangan (GAP)}

Setelah mengetahui nilai rata - rata dari maturity level saat ini dan nilai dari maturity level yang diharapkan, pada tahap ini dilakukan penghitungan nilai kesenjangan (Gap). Tabel 5 dibawah ini menujukkan gap antara tingkat kematangan saat ini dengan tingkat kematangan yang diharapkan, sebagai berikut :

TABEL 5

TABEL TINGKAT KESENJANGAN

\begin{tabular}{|l|c|c|c|}
\hline \multirow{2}{*}{\begin{tabular}{l}
\multicolumn{1}{|c|}{$\begin{array}{c}\text { Detail Control } \\
\text { Objective }\end{array}$} \\
\cline { 2 - 4 }
\end{tabular}} & (As-Is) & (To-Be) & GAP \\
\hline $\begin{array}{l}\text { DS5.1 } \\
\text { Manajemen } \\
\text { Keamanan TI }\end{array}$ & 1 & 4 & $4-1=3$ \\
\hline $\begin{array}{l}\text { DS5.3 } \\
\text { Manajemen } \\
\text { Identitas }\end{array}$ & 2 & 4 & $4-2=2$ \\
\hline $\begin{array}{l}\text { DS5.6 } \\
\text { Definisi Insiden } \\
\text { Keamanan }\end{array}$ & 2 & 4 & $4-2=2$ \\
\hline DS5.7 & 2 & 4 & $4-2=2$ \\
$\begin{array}{l}\text { Perlindungan } \\
\text { Teknologi } \\
\text { Keamanan }\end{array}$ & 2 & 4 & $4-2=2$ \\
\hline $\begin{array}{l}\text { DS11.1 } \\
\text { Persyaratam Bisnis } \\
\text { untuk Manajemen } \\
\text { Data }\end{array}$ & 2 & 4 & $4-2=2$ \\
\hline $\begin{array}{l}\text { DS11.4 } \\
\text { Pembuangan }\end{array}$ & 2 & & \\
\hline $\begin{array}{l}\text { DS11.5 } \\
\text { Pencadangan dan }\end{array}$ & & 4 & \\
\hline
\end{tabular}

Dari Tabel 5 diatas, hasil hasil dari pengurangan antara tingkat kematangan saat ini dan tingkat kematangan yang diharapkan pada proses DS5 (Memastikan Keamanan Sistem) dan DS11 (Kelola Data) mendapatkan keseluruhan hasil rata - rata nilai kesenjangan (gap) dari semua detail control objective 
pada DS5 dan DS11 yaitu 2,00 yang berarti termasuk ke dalam level 2 (Berulang).

\section{KESIMPULAN}

Berdasarkan hasil penelitian yang telah dilakukan oleh penulis maka dapat diambil kesimpulan dari hasil analisa yang dilakukan oleh penulis pada E-Dishub bidang sub bagian umum dan kepegawaian Dinas Perhubungan Kota Surabaya nilai rata-rata maturity level pada domain DS5 yaitu didapatkan nilai 1,75 yang berarti nilai tersebut masuk ke dalam level 2 (berulang). Pada domain DS11 didapatkan nilai 2,0 yang berarti nilai tersebut masuk ke dalam level 2 (berulang). Hasil dari penelitian ini adalah rekomendasi perbaikan pengembangan tata kelola teknologi informasi pada E-Dishub pada Sub Bagian Umum dan Kepegawaian Dinas Perhubungan Kota Surabaya.

\section{UCAPAN TERIMA KASIH}

Terimakasih kepada Program Studi Informatika UPN "Veteran" Jawa Timur yang telah menyelenggarakan seminar ini dalam kondisi keterbatasan saat Pandemi COVID19.

\section{REFERENSI}

[1] Carolina, I., Pengukuran Tingkat Maturity Tata Kelola TI berdasarkan Domain PO Dan AI Menggunakan Cobit 4.1 (Studi kasus : Maharaja Ban Jakarta), 2014

[2] Dinas Pehubungan, "Profil Dinas Perhubungan Kota Surabaya.

[3] Rencana Strategis Dinas Perhubungan Kota Surabaya Tahun 20162021”, Dinas Perhubungan, 2018.

[4] IT Governance Institude (ITGI), “COBIT 4.1,” Rolling Meadow: IT Governance Institude, 2007.

[5] Arumana, A. Rochim, A. F. \& Windasari, I. P. (2014). Analisis Tata Kelola Teknologi Informasi Mengunakan Kerangka Kerja Cobit 4.1 Pada Fakultas Teknik Undip.

[6] ISACA. (2007). Cobit 4.1. 